\title{
Perfusion lung scintigraphy for the prediction of postoperative residual pulmonary function in patients with lung cancer
}

Katarzyna Kovačević-Kuśmierek¹, Józef Kozak², Łukasz Pryt², Małgorzata Bieńkiewicz¹, Paweł Cichocki³ ${ }^{3}$ Jacek Kuśmierek³ Anna Płachcińska ${ }^{1}$

${ }^{1}$ Department of Quality Control and Radiological Protection, Medical University of Łódź, Poland

${ }^{2}$ Word of Thoracic Surgery and Respiratory Rehabilitation, N. Copernicus District Hospital in Łódź, Poland

${ }^{3}$ Department of Nuclear Medicine, Medical University of Łódź, Poland

Supporters: Medical University of Łódź, Poland

[Received 19 II 2015; Accepted 3 VII 2015]

\begin{abstract}
BACKGROUND: Accurate prediction of postoperative pulmonary function in patients with non-small cell lung cancer is crucial for proper qualification for surgery, the only effective therapeutic method. The aim of the study was to select the most accurate method for acquisition and processing of lung perfusion scintigraphy (LPS) combined with spirometry for prediction of postoperative pulmonary function in patients qualified for surgery.

MATERIAL AND METHODS: LPS was performed in 70 patients (40 males, 30 females), with preoperative spirometry (mean $F E V 1_{\text {preop }}=2.26 \pm 0.72 \mathrm{~L}$ ), after administration of $185 \mathrm{MBq}$ of ${ }^{99 \mathrm{mTC}-m i c r o a l b u m i n} / \mathrm{macroaggregate}$, using planar (appa) and SPECT/CT methods. Predicted postoperative lung function ( $F E V 1_{\text {pred }}$ ) was calculated as a part of active lung parenchyma to remain after surgery. A non-imaging segment counting method was also applied. FEV1 $1_{\text {pred(appa, SPECT, SPECT/CT, segm.) }}$ were further compared with actual $F E V 1_{\text {postop }}$ values obtained from postoperative spirometry.

RESULTS: In the whole studied group (47 lobectomies, 23 pneumonectomies) mean value of FEV1 $1_{\text {postop }}$ was equal to 1.76 ( \pm 0.56) L. FEV1 ${ }_{\text {pred(appa, SPECT, SPECT/CT, segm.) }}$ were equal to $1.75( \pm 0.58) \mathrm{L}, 1.71( \pm 0.57) \mathrm{L}, 1.72( \pm 0.57) \mathrm{L}$ and 1.57 ( \pm 0.58$) \mathrm{L}$, respectively. A segment counting method systematically lowered predicted FEV1 values $\left(p<10^{-5}\right)$. Moreover, in 31 patients with $\mathrm{FEV} 1_{\text {preop }}<2 \mathrm{~L}$ error of predicted values was assessed with Bland-Altman method. Mean absolute differences $\mathrm{FEV} 1_{\text {postop }}$ - FEV1 $1_{\text {pred }}$ amounted to: appa - $(0.04 \pm 0.13) \mathrm{L}$, SPECT - $(0.07 \pm 0.14) \mathrm{L}, \mathrm{SPECT} / \mathrm{CT}-(0.06 \pm 0.14) \mathrm{L}$ and segm. $-(0.21$ $\pm 0.19) \mathrm{L}$, respectively. Lower limit of $95 \%$ confidence interval calculated for planar - optimal method, was equal to $-220 \mathrm{~mL}$ (also determined separately in subgroups after lobectomy and pneumonectomy).

CONCLUSIONS: This study shows that planar LPS may be applied for prediction of postoperative pulmonary function in patients qualified for pneumonectomy and lobectomy. If actual FEV $1_{\text {postop }}$ value is to be $\geq 800 \mathrm{~mL}$, predicted value should exceed $1000 \mathrm{~mL}$.
\end{abstract}

\section{KEY words: carcinoma, lung, perfusion imaging, pneumonectomy, scintigraphy, SPECT}

Nuclear Med Rev 2015; 18, 2: 70-77

\section{Background}

Non-small cell lung cancer (NSCLC) provides one of the most frequent indications for lung parenchyma resection. Patients qualified for surgical intervention should undergo examinations of their respiratory sufficiency. Diagnostic methods should take into account patient condition and risk factors resulting from coexisting diseases, especially of lungs and a circulatory system. A thorough examination

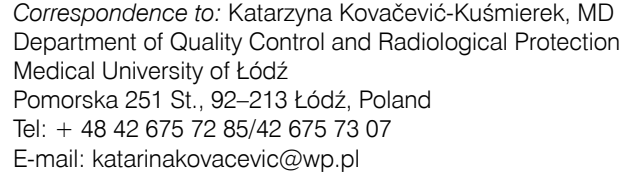

of these patients aiming at a maximal reduction of postoperative complications and mortality is particularly important [1, 2].

Spirometry, gasometry, diffusing capacity for carbon monoxide $\left(\mathrm{DL}_{\mathrm{co}}\right)$ and stress tests with assessment of maximal oxygen consumption $\left(\mathrm{VO}_{2 \max }\right)$ are most important studies examining patient respiratory sufficiency. Spirometric study is considered the most essential and also easily available one. It provides an index referred to as a forced expiratory volume in one second (FEV1), a widely accepted in clinical practice index of respiratory sufficiency. It is assumed that absolute values of FEV1 in patients qualified for lobectomy and pneumonectomy should not be lower than $1500 \mathrm{~mL}$ and $2000 \mathrm{~mL}$, respectively, or these values should exceed $80 \%$ of values predicted for patient age, height, gender and body mass. $[3,4]$. When FEV1 value is close to its lower limit, pointing to a high risk of postoperative complications, preoperative patient 


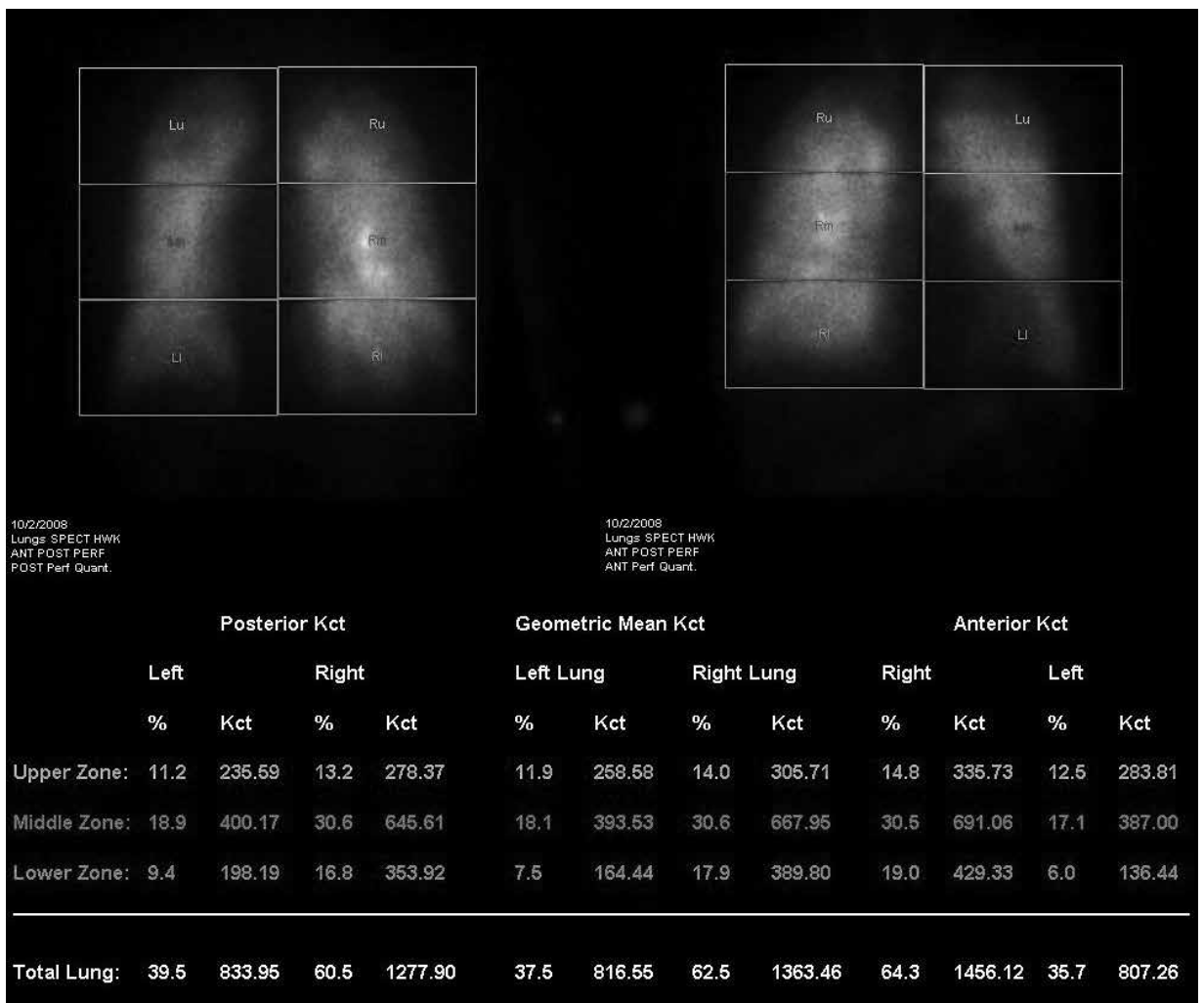

Figure 1. A planar study. An example of an automatic lung division into regions of interest in posterior and anterior projections and calculation of percentages of respective lobes in an overall lung function. Applied modifications of this algorithm are described in text

diagnosis should be supplemented with methods predicting post-operative FEV1 value. It is assumed that a risk following lung parenchyma resection is acceptable when predicted FEV1 value lies in the range between $800-1000 \mathrm{~mL}$. Its lower values decide against the surgery [5-7].

Among methods used for prediction of post-operative FEV1 values a very simple method based of segment counting should be mentioned [8], but also imaging methods, like lung perfusion and ventilation scintigraphy, also a quantitative computed tomography and a dynamic magnetic resonance imaging are used. Scintigraphic studies play a particularly important role among those methods $[9,10]$.

The aim of this work was to determine which of methods used for acquisition and processing of lung perfusion scintigraphy applied together with pre-operative spirometry gives the most accurate results of predicted post-operative FEV1 values in NSCLC patients qualified for lung parenchyma resection.

\section{Material and methods}

Studies were performed in 70 patients with NCSLC ( 40 males and 30 females) at the age between 37 and 80 years (mean value $61.1 \pm 8.7$ years), prepared for anatomical (removal of the lobe or a whole lung) resection of pulmonary parenchyma. All patients had a pre- and a post-operative spirometry, which was performed 3 to 6 months after surgery $[11,12]$. Lung perfusion scintigraphy have been conducted using a dual head gamma camera Infinia Hawkeye (by General Electric) after intravenous injection of $185 \mathrm{MBq}$ of ${ }^{99 \mathrm{~m}} \mathrm{Tc}-\mathrm{microalbumin} /{ }^{99 \mathrm{~m}} \mathrm{Tc}-\mathrm{macroaggregaate}$, applying a planar method in anterior and posterior projections (AP and PA) and SPECT/CT acquisition. In order to assure a proper radiopharmaceutical distribution in lungs, a half of its quantity was administered to a patient in a prone and another half in a supine position, in agreement with literature recommendations [13]. Planar study (appa) acquisition, lasting $300 \mathrm{sec}$., was performed in a $256 \times 256$ matrix. Study was processed using an automatic software Quantitative Perfusion Analysis being at disposal on Xeleris image processing station. This software divides both lungs into 3 regions of interest, in AP and PA projections, in a fully automatic way (Fig. 1). Then it calculates geometric mean values from both projections in all six ROls. Authors of this study modified those calculations in such a way that, before calculation of geometric mean values, counts collected from a middle region of a left lung in PA projection were added to lower lobe and in AP projection - to upper lobe. This modification was intended to adjust calculated values to lung anatomy (left lung has only two lobes). Afterwards percentages of all pulmonary lobes in a total lung function and a percentage of a part planned to remain after surgery were calculated.

SPECT study, applied as another method for prediction of a post-operative lung function, was acquired in a $360^{\circ}$ angle of rotation. Raw study consisted of 120 images acquired in a $128 \times 128$ matrix. SPECT method was supplemented with a low dose CT (voltage $140 \mathrm{kV}$, current $2.5 \mathrm{~mA}$ ) study acquired with the same hybrid gamma camera. SPECT images were reconstructed with an iterative OSEM method ( 2 iterations, 10 subsets) and with Hann filter (cutoff frequency 0.9 cycle/cm). Regions of interest encompassing lobes of the right and left lung (Fig. 2A and B) were drawn manually, on 12 sagittal slices, making use of anatomical 


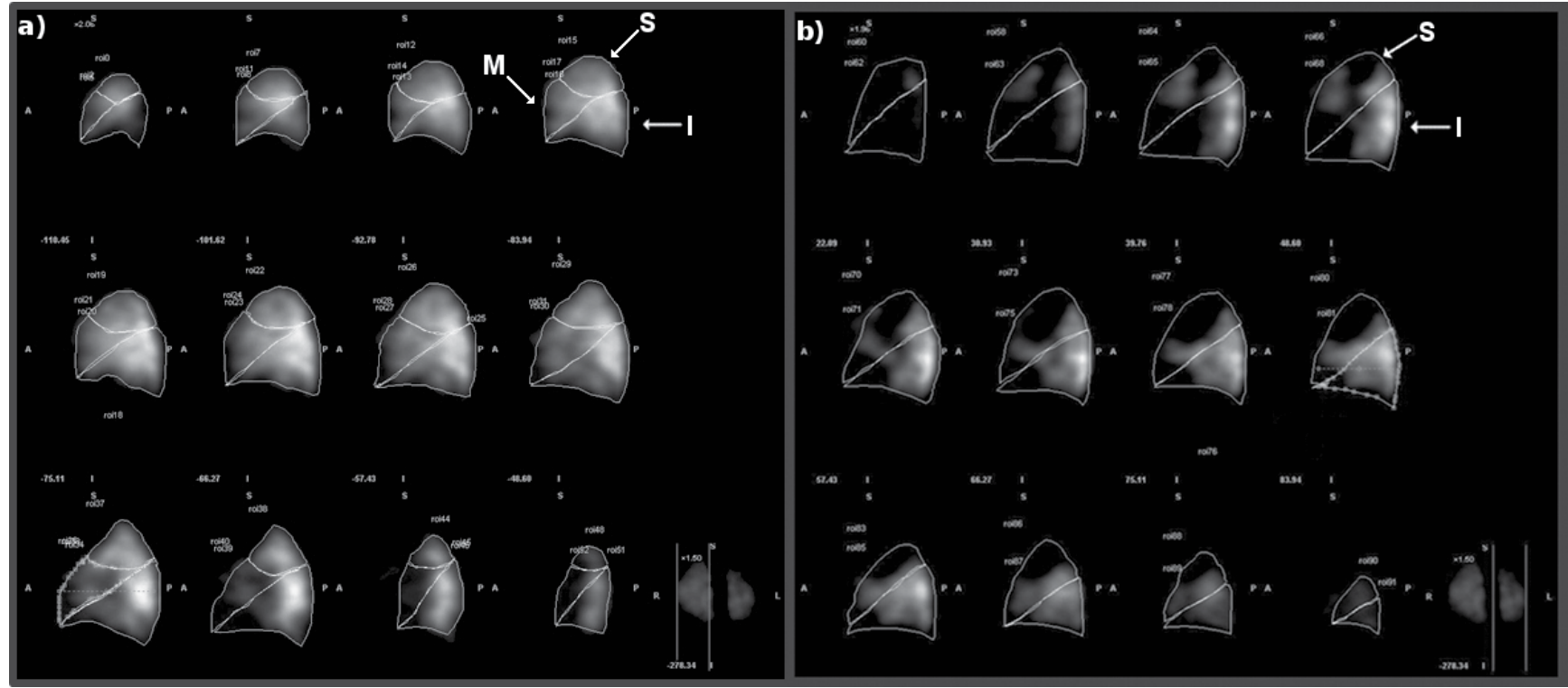

Figure 2A, B. A SPECT study: A. Division of the right lung into lobes -12 sagittal slices with regions encompassing superior (S), middle (M) and inferior (I) lobes; B. Division of the left lung into lobes - 12 sagittal slices with regions encompassing superior (S) and inferior (I) lobes

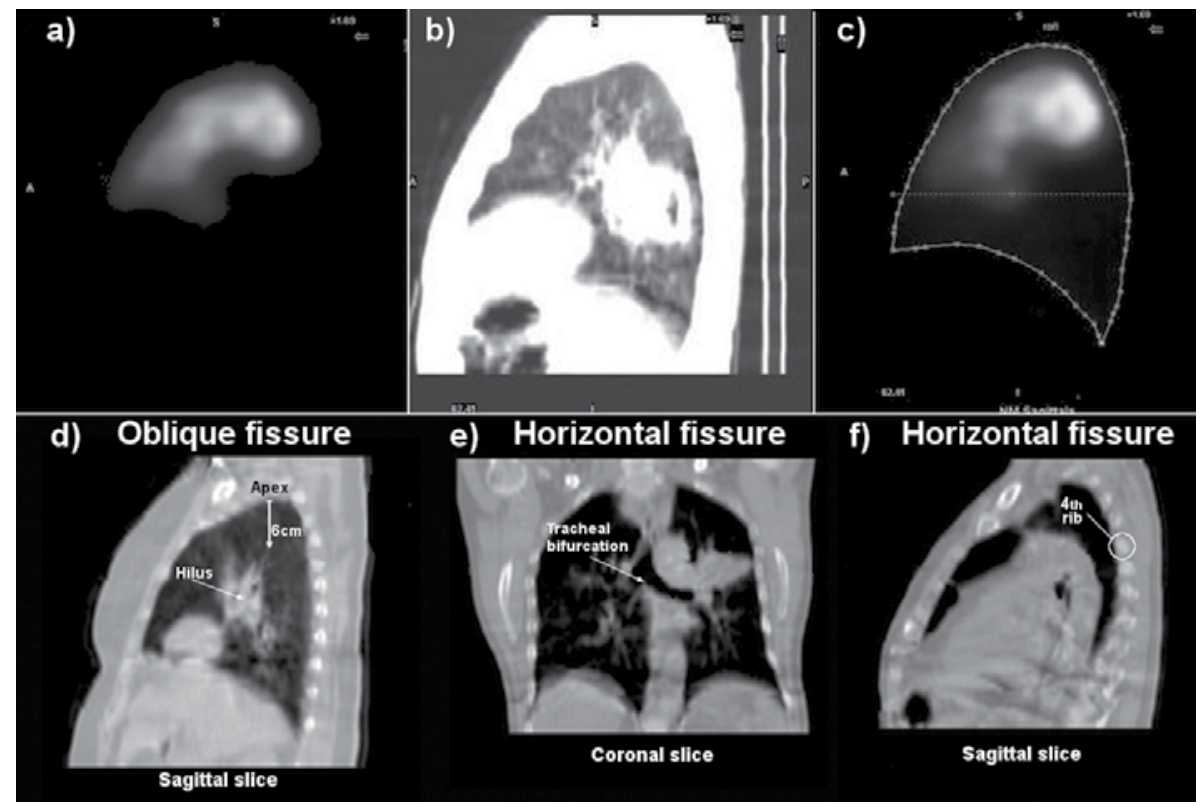

Figure 3A-F. A SPECT/CT study: usefulness of CT study in contouring lungs and finding anatomical landmarks specific for interlobar fissures: A. Radiopharmaceutical cumulated in a left lung visible in a sagittal slice of a SPECT study; B. A contour of this lung visible in sagittal slice of CT study; C. Delineation of a contour of this lung in SPECT study based on CT image; D-F. An anatomical point located $6 \mathrm{~cm}$ below a lung apex, on the upper-posterior surface of the lung hilus (D), which should be crossed by an oblique fissure, tracheal bifurcation (E) and a fourth rib (F) anatomical points helping in a proper delineation of a horizontal fissure

schemes presenting division of lungs into lobes. Counts collected inside specific ROls were used for calculation of percentages of pulmonary lobes in a total lung function.

A third method applied for prediction of post-operative lung function was a SPECT/CT study, in which reconstructed CT images were used as a support for lung contouring (Fig. 3A-C) and helped in a proper delineation of courses of interlobar fissures (Fig. 3). As a low dose CT does not visualize those fissures, CT images helped in determination of their courses in an indirect way, by showing specific anatomical points. An operator delineated lung lobes on SPECT sagittal slices looking at the same time at reconstructed CT slices. An oblique fissure was drawn in such a way that it crossed a specific point visible on a sagittal CT image, located $6 \mathrm{~cm}$ below a pulmonary apex, on the upper- posterior surface of the lung hilus (Fig. 4D). Drawing a horizontal fissure, an operator also watched CT sagittal and coronal slices in order to pass this fissure through a fourth rib and tracheal bifurcation level (Fig. 4E, F). [14]. 

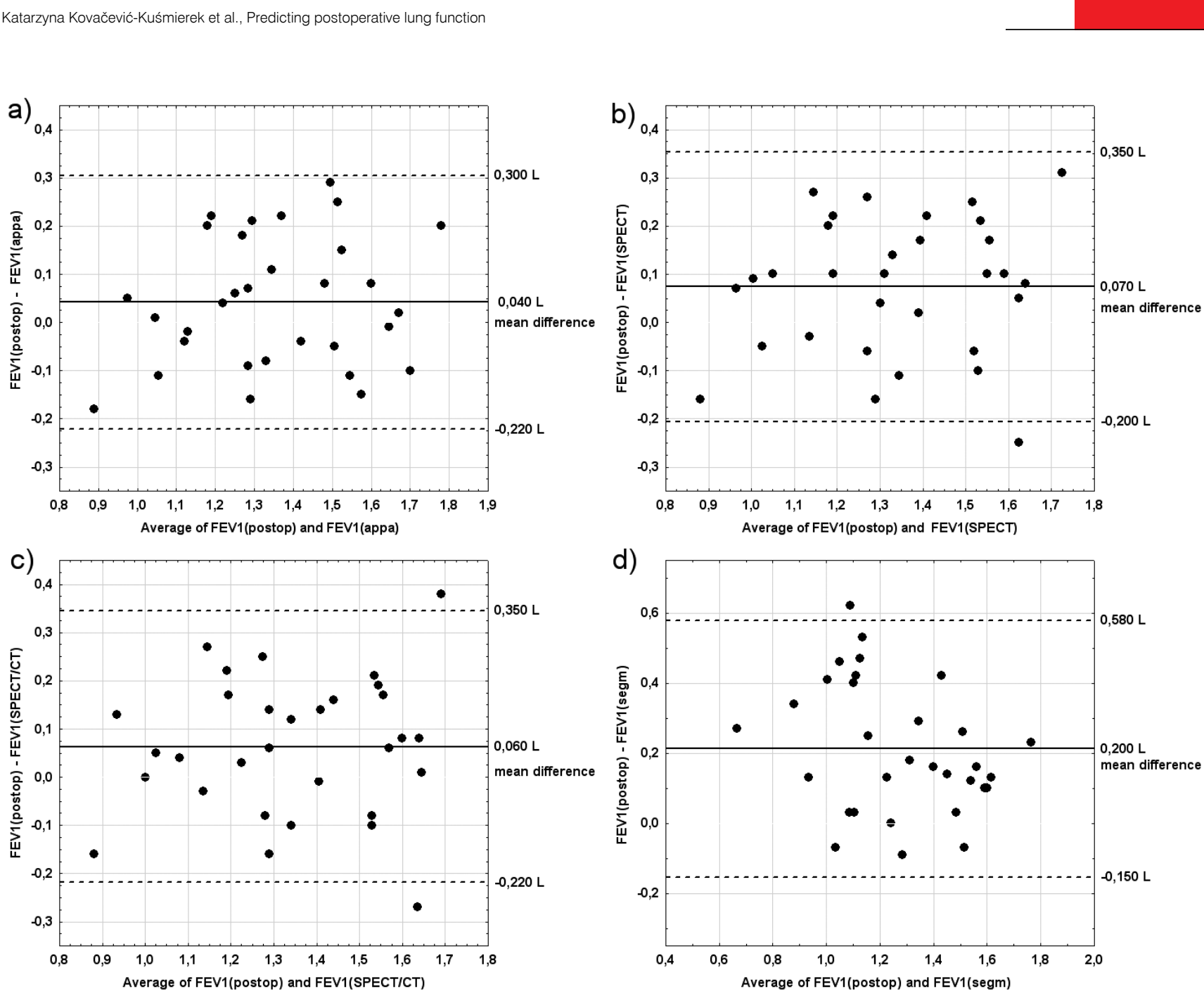

Figure 4A-D. Bland-Altman plots comparing FEV1 $1_{\text {postop }}$ and $\mathrm{FEV} 1_{\text {pred }}$ obtained in 31 patients with preoperative values below $<2$ liters calculated using: A. Planar-appa; B. SPECT; C. SPECT/CT; D. Segment counting methods

Predicted post-operative FEV1 ${ }_{\text {pred }}$ values were calculated according to the following formula:

$$
\begin{aligned}
& \text { FEV } 1_{\text {pred (appa, SPECT and SPECT/CT) }}=\mathrm{FEV} 1_{\text {preop }} \times \text { percentage } \\
& \text { of lung parenchyma to remain. }
\end{aligned}
$$

The above presented methods using lung perfusion scintigraphy were additionally compared with a conventional method of segment counting (segm.) assuming that every segment has the same contribution to a total lung function. This method, introduced in 1975 by Juhl and Frost [8], is based on calculation of a percentage of segments planned to remain after a surgery, according to the formula:

$$
F E V 1_{\text {segm }}=F E V 1_{\text {preop }} \times(1-\mathrm{s} / 19)
$$

where „, denotes number of segments planned to be removed and 19 - a total number of segments (3 in upper, 2 in middle and 5 in lower lobe of the right lung and 5 in upper and 4 in lower lobe of the left lung).

Values of postoperative FEV1 predicted with all four methods (appa, SPECT, SPECT/CT and segm.) were compared with actual post-operative values obtained from spirometry in the whole group as well as subgroups of patients, taking into account a type of surgery (lobectomy or pneumonectomy), operated lung (right or left) and location of removed lobes (upper or lower).

Moreover, in 31 patients with preoperative FEV1 values lower than 2 liters (close to limit values for anatomical resection of lung parenchyma) errors of predicted values were estimated.

\section{Statistical analysis}

Test hypothesis for distributions of FEV1 values was verified with use of nonparametric methods, the Mann-Whitney $U$ test (for independent data) or the Wilcoxon test (for matched observations). Differences between predicted and actual values of FEV1 were assessed with parametric Student's t-test.

A graphical method of the Bland-Altman plot was used to compare FEV1 values obtained from predictions and post-operative measurements (with certain systematic and random errors). Intervals of agreement were drawn as the mean difference between predicted and measured values plus and minus 1.96 times the standard deviation of the differences.

Strength of linear relationship between predicted and measured FEV1 values was quantified by the Pearson correlation coefficients with significance based on $t$-statistics. 
Table 1. Descriptive statistics for FEV1 values measured postoperatively and predicted with four applied methods - in the whole study group and after subdivision according to a surgery extent (lobectomy/pneumonectomy)

\begin{tabular}{|c|c|c|c|c|c|}
\hline & & $\mathbf{n}$ & Mean & SD & $P\left(\right.$ vs FEV $\left.1_{\text {postop }}\right)$ \\
\hline \multirow[t]{3}{*}{ FEV $1_{\text {postop }}$} & All & 70 & 1.76 & 0.56 & - \\
\hline & Lobectomy & 47 & 1.88 & 0.60 & - \\
\hline & Pneumonectomy & 23 & 1.52 & 0.38 & - \\
\hline \multirow{3}{*}{$F E V 1_{\text {appa }}$} & All & 70 & 1.75 & 0.58 & 0.55 \\
\hline & Lobectomy & 47 & 1.90 & 0.61 & 0.38 \\
\hline & Pneumonectomy & 23 & 1.44 & 0.37 & 0.03 \\
\hline \multirow[t]{3}{*}{$F E V 1_{\text {SPECT }}$} & All & 70 & 1.71 & 0.57 & 0.02 \\
\hline & Lobectomy & 47 & 1.85 & 0.60 & 0.20 \\
\hline & Pneumonectomy & 23 & 1.43 & 0.37 & 0.02 \\
\hline \multirow[t]{3}{*}{$F E V 1_{\text {SPECT/CT }}$} & All & 70 & 1.72 & 0.57 & 0.07 \\
\hline & Lobectomy & 47 & 1.86 & 0.59 & 0.58 \\
\hline & Pneumonectomy & 23 & 1.43 & 0.38 & 0.03 \\
\hline \multirow[t]{3}{*}{ FEV1 ${ }_{\text {(SEGM) }}$} & All & 70 & 1.57 & 0.58 & $<0.00001$ \\
\hline & Lobectomy & 47 & 1.76 & 0.57 & 0.00 \\
\hline & Pneumonectomy & 23 & 1.18 & 0.40 & 0.00 \\
\hline
\end{tabular}

SD — standard deviation

In all analyses, statistical significance was achieved for a $\mathrm{p}$ value $\leq 0.05$. Calculations were performed by means of Statistica 10.0 software.

\section{Results}

In 43 patients a lobectomy was performed (of upper left lobe -5 , lower left -8 , upper right -21 and lower right -9 ), in 4 patients bilobectomy (lower -3 and upper -1 ) and in 23 patients - pneumonectomy (left -16 and right -7 patients).

Correlation coefficients between results of radionuclide methods ( $F E V 1_{\text {appa }}, F E V 1_{\text {SPECT }}$ and FEV1 $\left.1_{\text {SPECT/CT }}\right)$ and actual postoperative values ( $\left.F E V 1_{\text {postop }}\right)$ were high and equal to: $0.909,0.914$ and 0.913, respectively. Correlation coefficient for a segment counting method was also high -0.905 .

Mean values of predicted FEV1 were very similar to actual values for appa method -1.75 vs $1.76(p=0.55)$, and for SPECT and SPECT/CT methods predicted values were slightly lowered -1.71 vs $1.76(p=0.02)$ and 1.72 vs $1.76(p=0.07)$, respectively. However, postoperative FEV1 values predicted by a segment counting method were considerably lowered - 1.57 vs $1.76(p<0.00001)$ (Table 1).

Accuracies of FEV1 prediction calculated separately in subgroups of patients qualified for lobectomy and pneumonectomy are presented in Table 1. For lobectomy values predicted by all three scintigraphic methods did not differ significantly from actual ones, and for pneumonectomy predictions of all these methods were slightly, although statistically significantly lowered. However, a segment counting method predicted FEV1 values considerably and statistically significantly lower than actual ones, both in case of lobectomy and pneumonectomy -1.76 vs $1.88(p=0.0001)$ and 1.18 vs 1.52 ( $p=0.00003)$, respectively.

Tables 2 and 3 present comparisons between predicted and actual post-operative FEV1 values separately in patients who underwent left and right lung surgery. In subgroup of patients after a right
Table 2. Descriptive statistics for FEV1 values measured postoperatively and predicted with four applied methods in patients after pneumonectomy - separately for left and right lung

\begin{tabular}{|c|c|c|c|c|c|}
\hline & Side & $\mathrm{n}$ & Mean & SD & $p$ \\
\hline \multirow[t]{2}{*}{$F E V 1_{\text {postop }}$} & Left & 16 & 1.50 & 0.41 & - \\
\hline & Right & 7 & 1.56 & 0.32 & - \\
\hline \multirow[t]{2}{*}{ FEV $1_{\text {appa }}$} & Left & 16 & 1.45 & 0.39 & 0.22 \\
\hline & Right & 7 & 1.41 & 0.34 & 0.02 \\
\hline \multirow[t]{2}{*}{ FEV $1_{\text {SPECT }}$} & Left & 16 & 1.43 & 0.40 & 0.12 \\
\hline & Right & 7 & 1.44 & 0.31 & 0.02 \\
\hline \multirow[t]{2}{*}{ FEV1 $1_{\text {SPECT/CT }}$} & Left & 16 & 1.43 & 0.41 & 0.16 \\
\hline & Right & 7 & 1.43 & 0.32 & 0.03 \\
\hline \multirow[t]{2}{*}{$F E V 1_{\text {SEGM }}$} & Left & 16 & 1.17 & 0.43 & 0.00 \\
\hline & Right & 7 & 1.21 & 0.34 & 0.02 \\
\hline
\end{tabular}

SD — standard deviation

Table 3. Descriptive statistics for FEV1 values measured postoperatively and predicted with four applied methods in patients after lobectomy - separately for left and right lung

\begin{tabular}{|c|c|c|c|c|c|}
\hline & Side & $\mathrm{n}$ & Mean & SD & $p$ \\
\hline \multirow[t]{2}{*}{ FEV1 $1_{\text {postop }}$} & Left & 13 & 1.67 & 0.48 & - \\
\hline & Right & 34 & 1.96 & 0.63 & - \\
\hline \multirow[t]{2}{*}{ FEV1 ${ }_{\text {appa }}$} & Left & 13 & 1.62 & 0.52 & 0.53 \\
\hline & Right & 34 & 2.00 & 0.62 & 0.16 \\
\hline \multirow[t]{2}{*}{ FEV $1_{\text {SPECT }}$} & Left & 13 & 1.68 & 0.53 & 0.83 \\
\hline & Right & 34 & 1.92 & 0.62 & 0.07 \\
\hline \multirow[t]{2}{*}{$F E V 1_{\text {SPECT/CT }}$} & Left & 13 & 1.66 & 0.49 & 0.83 \\
\hline & Right & 34 & 1.94 & 0.62 & 0.42 \\
\hline \multirow[t]{2}{*}{ FEV $1_{\text {SEGM }}$} & Left & 13 & 1.58 & 0.46 & 0.09 \\
\hline & Right & 34 & 1.83 & 0.60 & 0.00 \\
\hline
\end{tabular}

SD — standard deviation

lung pneumonectomy values of FEV1 predicted with all three methods of lung perfusion scintigraphy were statistically significantly lowered although a significance level was only slightly below the accepted limit value. In the subgroup of patients after lobectomy no significant differences between predicted and measured FEV1 values were found for scintigraphic methods.

In a subgroup of patients with lobectomies no differences between accuracies of prediction of FEV1 values by scintigraphic methods between upper and lower lobectomies were found (Table 4).

Systematic and random errors of FEV1 values predicted in 31 patients with preoperative values lower than 2 liters were close to each other for three scintigraphic methods. Mean, absolute differences $F E V 1_{\text {postop }}-F E V 1_{\text {pred }}$ and standard deviations were equal to: for appa $-0,04, \pm 0,13 \mathrm{~L}$ (in a subgroup of patients with lobectomy and pneumonectomy $0.02 \pm 0.12 \mathrm{~L}$ and $0.07 \pm 0.15 \mathrm{~L}$, respectively); for SPECT $-0.07 \pm 0.14$; for SPECT/CT $-0.06 \pm 0.14$. However, for a segment counting method a mean difference as well as a standard deviation were larger: $0.21 \pm 0.19$. Lower limits of $95 \%$ confidence intervals calculated for differences between measured postoperative and predicted FEV1 values assessed with a Bland-Altman method amounted to: for appa -0,220 L (the same values were obtained in subgroups of patients with lobectomies and pneumonectomies); for SPECT: -0,200 L; for SPECT/CT: 
Table 4. Descriptive statistics for FEV1 values measured postoperatively and predicted with four applied methods in patients after lobectomy — separately for upper and lower lobes

\begin{tabular}{|c|c|c|c|c|c|}
\hline Lobectomy & Lobe & $\mathbf{n}$ & Mean & SD & $p$ (vs FEV $\left.1_{\text {postop }}\right)$ \\
\hline \multirow[t]{2}{*}{$F E V 1_{\text {postop }}$} & Upper & 27 & 2.05 & 0.65 & - \\
\hline & Lower & 20 & 1.66 & 0.45 & - \\
\hline \multirow[t]{2}{*}{$F E V 1_{\text {appa }}$} & Upper & 27 & 2.10 & 0.64 & 0.21 \\
\hline & Lower & 20 & 1.63 & 0.46 & 0.99 \\
\hline \multirow[t]{2}{*}{ FEV $1_{\mathrm{SPECT}}$} & Upper & 27 & 2.02 & 0.66 & 0.22 \\
\hline & Lower & 20 & 1.63 & 0.41 & 0.61 \\
\hline \multirow[t]{2}{*}{ FEV $1_{\text {SPECT/CT }}$} & Upper & 27 & 2.03 & 0.66 & 0.56 \\
\hline & Lower & 20 & 1.63 & 0.39 & 0.87 \\
\hline \multirow[t]{2}{*}{$\mathrm{FEV} 1_{\mathrm{SEGM}}$} & Upper & 27 & 1.97 & 0.60 & 0.05 \\
\hline & Lower & 20 & 1.48 & 0.37 & 0.00 \\
\hline
\end{tabular}

$\mathrm{SD}$ - standard deviation

$-0,220 \mathrm{~L}$; for segment counting: $-0,150 \mathrm{~L}$ (Table 4). These values were accepted as maximal errors of predicted FEV1 values. Moreover, to be able to compare results of the present work with outcomes of studies presented in the literature, in this subgroup of 31 patients a relative per cent error for differences $F E V 1_{\text {postop }}$ - FEV1 $1_{\text {pred }}$ obtained with a planar method has been calculated. It amounted to $2.8 \pm 10.3(\%)$, and in subgroups of patients with lobectomies and pneumonectomies $-0.91 \pm 8.4(\%)$ and $5.5 \pm 1$ $2.9(\%)$, respectively.

\section{Discussion}

Guidelines of the American Thoracic Society as well as common guidelines issued by the European Respiratory Society and the European Society of Thoracic Surgeons recommend a segment counting method to be used for prediction of post-operative lung function in patients qualified for lobectomy. Only in case of planned pneumonectomy a planar lung perfusion scintigraphy can be applied according to authors of these guidelines [1,2]. This is due to presumed larger error of the scintigraphic method in assessment of contribution of lobes to a total lung function. However, a recent publication by Win et al. [15], presenting results of studies performed in 61 patients with preoperative FEV1 values below 1.5 liter qualified for lobectomy did not reveal a statistically significant difference between accuracies of segment counting and planar lung perfusion scintigraphy methods. Another publication, by Bolliger et al. [16], showed that planar perfusion scintigraphy was more accurate than segment counting in prediction of postoperative lung function in patients qualified for lobectomy as well as pneumonectomy. Authors of this work present an opinion that a segment counting method can be applied only in case of planning a resection of only one lobe, with a mandatory consideration of dysfunctional segments. Our work revealed a significant reduction of FEV1 values predicted by segment counting method as compared with post-operative measurements: 1.18 vs $1.52(p=0.00003)$ in case of pneumonectomies and 1.76 vs $1.88(p=0.0001)$ in case of lobectomies and for this reason application of this method in our opinion should be limited.

Giordano et al. [17] compared accuracies of prediction of post-operative lung function in 20 patients qualified for pneumonec- tomy and 23 - for lobectomy. Results obtained in a subgroup after lobectomy were not worse than those after pneumonectomy [17]. The same authors in another publication [6] using the same method predicted postoperative FEV1 values in 41 patients qualified for a lobectomy. They obtained less accurate results in left than in right and upper than lower lobectomies. As a result authors of this publication recommended "safe" limits for predicted postoperative FEV1 values as 1.2 liter for upper and 1 liter for lower lobectomies. It should be emphasized, however, that a study group used in this work was small and therefore a credibility of these results is rather limited. Predicted FEV1 values obtained in the present work were closer to real values in case of lobectomies than pneumonectomies. Moreover, in case of right pneumonectomies postoperative FEV1 values predicted by all scintigraphic methods were slightly, although statistically significantly underestimated. On the other hand, a comparison between predicted FEV1 values in case of left and right as well as upper and lower lobectomies failed to reveal any statistically significant differences between their accuracies.

In a literature presenting results of assessment of accuracy of FEV1 predicted values by means of a planar lung perfusion study, quite differentiated findings can be met. Bolliger et al. [16] studied 44 patients and obtained a variability of results calculated according to a Bland Altman method included in an interval between -0.5 and 0.43 liter, a range wider than obtained in the present study: $(-0,22 ; 0,31)$ liter. Wu et al. [18] assessed accuracy of predicted FEV1 values by means of relative errors (mean value and a standard deviation), which amounted to $5.4 \pm 14.1$ (\%) for pneumonectomy and $0.82 \pm 15.5 \%$ for lobectomy. These values were close to ours in case on pneumonectomy and larger for lobectomy.

Lung perfusion scintigraphy can be at present performed with three methods: planar - in (among others) anterior and posterior projections, tomographic — with single photon emission computed tomography (SPECT) and also with a hybrid SPECT/CT imaging, integrating functional and morphological information in one study. A SPECT method enables 3-dimensional imaging of lungs with better visualization of hypoperfused, even sub-segmental regions. Additional use of an anatomical image $-X$-ray computed tomography should facilitate lung division into lobes with subsequent assessment of their regional function. The expectation that a SPECT method, especially with help of CT images, should allow delineating lung lobes more precisely than a planar one, resulting in a more accurate prediction of a postoperative respiratory parameters seems intuitively justified. However, divergent opinions on this issue can be met in the literature. Caglar et al. [19] have shown that a thorough delineation of lung lobes in planar lung perfusion scintigrams does not improve accuracy of predicted postoperative FEV1 values as compared with a schematic division of lungs into lobes. Next, several authors applying both planar and SPECT methods did not observe any advantage of the latter in prediction of postoperative residual lung function [11, 12, 20]. However, Hirose et al. as well as Ohno et al. [21, 22] recognized SPECT as a more accurate method in prediction of postoperative FEV1 values. Another authors considered SPECT/CT to be the most accurate among scintigraphic methods in prediction of postoperative FEV1 values. It should be noted, however, that a CT method applied in these works was fully diagnostic, a feature that might have affected the accuracy of lung lobes delineation $[13,23,24]$. Analysis of results of our study did not reveal any advantage of SPECT or SPECT/CT 
methods over a planar one. It should be stressed again, that our study made use of a low dose CT that did not allow visualization of inter-lobar fissures.

Ohno et al. [21] inform about a high accuracy of SPECT perfusion study in prognosis of postoperative FEV1, confirmed by relative error (mean \pm standard deviation) equal to $5.1 \pm 7(\%)$ - lower than obtained in the present study. Also Mineo et al. [20] compared accuracy of planar and SPECT methods in a group of 39 patients and obtained absolute measures (mean \pm standard deviation) equal to $0.13 \pm 0.19 \mathrm{~L}$ and $0.05 \pm 0.18 \mathrm{~L}$, respectively, values higher than in the present work. Moreover, Piai et al [12] and Mineo et al. [20] made use of Pearson linear correlation coefficients in assessment of accuracy of planar and SPECT methods in prediction of postoperative FEV1 values in patients prepared for pneumonectomy and lobectomy. In both studies correlation coefficients were high and close to each other for planar and SPECT methods, but they were lower, although statistically non-significantly, in subgroups of patients prepared for pneumonectomy than for lobectomy. Although in our work another statistical methods were used, we also obtained better prediction of postoperative FEV1 values in patients prepared for lobectomies than pneumonectomies.

A literature reveals that in some diagnostic centers prediction of postoperative FEV1 values is based on both, lung perfusion and ventilation studies [7, 15, 23, 25-27]. It should be mentioned here, however, that lung ventilation study is more difficult to perform due to its complicated methodology and it is also more expensive. Results of listed above studies reveal a slight, non-significant advantage of a ventilation over perfusion study. However, analysis of results of these studies show also that accuracy of postoperative FEV1 prediction depends on a radiopharmaceutical used for imaging of a regional lung ventilation imaging. Application of noble gases, like xenon-133 and krypton-81m, allows to obtain values closer to actual ones due to a better penetration of noble gases into pulmonary alveoli as compared with technetium-99m-labaled radiopharmaceuticals, like "Technegas" (Cyclomedica) — ultra fine dispersion of technetium-99m labeled carbon or ${ }^{99 m}$ Tc-DTPA (diethylenetriaminepantaacetic acid). All in all, most communications prove that a perfusion study (without ventilation) provides sufficient data for a correct prediction of postoperative residual pulmonary function. However, ventilation scintigraphy should be reserved for specific situations of tumor located in pulmonary hilus and also of advanced stage (III) of lung cancer. It was observed that in those situations perfusion and ventilation mismatches can be seen. In such cases perfusion defects are not only evoked by hypoxic pulmonary vasoconstriction, but also can be caused by tumor constricting pulmonary arteries [7, 15, 25]. For this reason predicted postoperative FEV1 values based on lung perfusion study can be overestimated and give rise to a wrong decision of performing a surgery.

A contemporary medical imaging, excepting scintigraphy, makes also use of radiological methods, like quantitative computed tomography and a dynamic magnetic resonance in a quantitative diagnosis of a regional lung function. Although a computed tomography has been applied for many years in pulmonary diagnostics, its application for a quantitative assessment of a regional lung function has been introduced recently. The same holds true for a dynamic magnetic resonance applied in assessment of regional lung perfusion. A literature reveals accuracy of both radiological methods being close to scintigraphic ones [13, 16, 18, 21, 23].
Although a computed tomography is applied in a diagnosis of lung diseases routinely, its use for a quantitative prediction of a residual postoperative lung function is limited. Application of a magnetic resonance imaging for prediction of postoperative FEV1 values is also limited due to its high cost and elaborate methods demanding advanced processing that cannot be performed with routinely available software $[21,28,29]$.

Results of our study show that accuracies of all applied scintigraphic methods in prediction of postoperative residual lung function are high and close to each other. Moreover, it turned out that the simplest, least laborious and time consuming and also most available planar method does not surrender to tomographic methods, SPECT and SPECT/CT, presenting lung parenchyma in three dimensions. This is why, in our opinion, a planar lung perfusion scintigraphy, together with a preoperative spirometry, should be applied in patients qualified for lung parenchyma resection, both pneumonectomy and lobectomy, especially those with high risk of perioperative complications.

\section{Conclusions}

A segment counting method systematically underestimate predicted FEV1 values and therefore its use should be limited. A planar lung perfusion method is considered optimal due to its high availability, low labor input and a short time necessary to acquire and process this study. Application of SPECT or SPECT/CT methods does not improve accuracy of prediction of residual lung function. Planar perfusion scintigraphy can be used for prediction of postoperative lung function in patients qualified for pneumonectomy and lobectomy. Results of our study indicate that assuming a postoperative actual FEV1 value not lower than $800 \mathrm{~mL}$, a predicted postoperative residual FEV1 value calculation based on preoperative spirometry and planar lung perfusion study should not fall below $1000 \mathrm{~mL}$.

\section{Acknowledgements}

The study was partly financed by the Young Investigators Fund No 502-03/1-136-03/502-14-064 of Medical University of Łódź.

\section{References}

1. Colice GL, Shafazand S, Griffin JP, Keenan R, Bolliger CT. Physiologic Evaluation of the patient with lung cancer being considered for resectional surgery: ACCP evidenced-based clinical practice guidelines ( $2^{\text {nd }}$ edition). Chest 2007; 132: 161S-177S.

2. Brunelli A, Charloux A, Bolliger CT et al. ERS/ESTS clinical guidelines on fitness for radical therapy in lung cancer patients(surgery and chemo-radiotherapy). Eur Respir J 2009; 34: 17-41.

3. Wyser C, Stulz P, Soler M et al. Prospective evaluation of an algorithm for the functional assessment of lung resection candidates. Am J Respir Crit Care Med 1999; 159: 1450-1456.

4. Beckles MA, Spiro SG, Colice GL, Rudd RM. The physiologic evaluation of patients with lung cancer being considered for resectional surgery. Chest 2003; 123: 105S-114S.

5. Olsen GN, Block AJ, Tobias JA. Prediction of postpneumonectomy pulmonary function using quantitative macroaggregate lung scanning. Chest 1974; 66: 13-16.

6. Giordano A, Calcagni ML, Meduri G, Valente S, Galli G. Perfusion lung scintigraphy for the prediction of postlobectomy residual pulmonary function. Chest 1997; 111: 1542-1547. 
7. Wernly JA, DeMeester TR, Kirchner PT et al. Clinical value of quantitative ventilation-perfusion lung scans in the surgical management of bronchogenic carcinoma. J Thorac Cardiovasc Surg 1980; 80: 535-543.

8. Juhl B, Frost N. A comparison between measured and calculated changes in the lung function after operation for pulmonary cancer. Acta Anaesthesiol Scand Suppl 1975; 75: 39-45.

9. Chiti A, Schreiner FAG, Crippa F, Pauwels EKJ, Bombardieri E. Nuclear medicine procedures in lung cancer. Eur J Nucl Med 1999; 26: 533-555.

10. Abdel-Dayem HM, Scott $A$, Macapinlac $H$, Larson $S$. Tracer imaging in lung cancer. Eur J Nucl Med 1994; 21: 57-81.

11. Imaeda $\mathrm{T}$, Kanematsu $\mathrm{M}$, Asada $\mathrm{S}$ et al. Prediction of pulmonary function after resection of primary lung cancer. Utility in inhalation-perfusion SPECT imaging. Clin Nucl Med 1995; 20: 792-799.

12. Piai DB, Quagliatto R Jr, Toro I et al. The use of SPECT in postoperative assessment of patients with lung cancer. Eur Respir J 2004; 24: 258-262.

13. Yoshimoto $\mathrm{K}$, Nomori $\mathrm{H}$, Mori $\mathrm{T}$ et al. Prediction of pulmonary function after lung lobectomy by subsegments counting, computed tomography, single photon emission computed tomography and computed tomography: a comparative study. Eur J Cardiothorac Surg 2009; 35: 408-413.

14. Marciniak T, Ziółkowski M, Dzimira E et al. Anatomia Prawidłowa Człowieka. Tom II. Wydanie III. Rada Uczelniana Zrzeszenia Studentów Polskich Akademii Medycznej. Wrocław 1991: 140-145.

15. Win T, Laroche CM, Groves AM et al. Use of quantitative lung scintigraphy to predict postoperative pulmonary function in lung cancer patients undergoing lobectomy. Ann Thorac Surg 2004; 78: 1215-1218.

16. Bolliger $\mathrm{CT}$, Gückiel $\mathrm{C}$, Engel $\mathrm{H}$ et al. Prediction of functional reserves after lung resection: comparison between quantitative computed tomography, scintigraphy, and anatomy. Respiration 2002; 69: 482-489.

17. Giordano A, Calgani ML, Rossi B et al. The scintigraphic prediction of residual lung function after lobectomy in patients with bronchial carcinoma. Radiol Med 1995; 89: 501-505.

18. Wu MT, Pan HB, Chiang AA et al. Prediction of postoperative lung function in patients with lung cancer: comparison of quantitative CT with perfusion scintigraphy. AJR 2002; 178: 667-672.

19. Caglar M, Kara M, Aksoy T et al. Is the predicted postoperative FEV1 estimated by planar lung perfusion scintigraphy accurate in patients undergoing pulmonary resection? Comparison of two processing methods. Ann Nucl Med 2010; 24: 447-453.

20. Mineo TC, Schillaci O, Pompeo E, Mineo D, Simonetti G. Usefulness of lung perfusion scintigraphy before lung cancer resection in patients with ventilatory obstruction. Ann Thorac Surg 2006; 82: 1828-1834.

21. Ohno $\mathrm{Y}, \mathrm{Koyama} \mathrm{H}$, Nogami $\mathrm{M}$ et al. Postoperative lung function in lung cancer patients: comparative analysis of predictive capability of MRI, CT and SPECT. AJR 2007; 189: 400-408.

22. Hirose $\mathrm{Y}$, Imaeda $\mathrm{M}$, Doi $\mathrm{H}$ et al. Lung perfusion SPECT in predicting postoperative pulmonary function in lung cancer. Ann Nucl Med 1993; 7: 123-126.

23. Ohno $\mathrm{Y}, \mathrm{Koyama} \mathrm{H}$, Takenaka $\mathrm{D}$ et al. Coregistered ventilation and perfusion SPECT using krypton-81m and Tc-99m-lebeled macroaggregated albumin with multislice CT: utility for prediction of postoperative lung function in non-small cell lung cancer patients. Acad Radiol 2007; 14: 830-838.

24. Yoshimoto K, Nomori H, Mori T et al. Quantification of the impact of segmentectomy on pulmonary function by perfusion single-photon-emission computed tomography and multidetector computed tomography. J Thorac Cardiovasc Surg 2009; 137: 1200-1205

25. Goulart DM, Barbotte E, Basurko C, Comte F, Rossi M. Accuracy and precision of perfusion lung scintigraphy versus ${ }^{133} \mathrm{Xe}$-radiospirometry for preoperative pulmonary functional assessment of patients with lung cancer. Eur J Nucl Med Mol Imaging 2006; 33: 1048-1054.

26. Win $\mathrm{T}$, Tasker $\mathrm{AD}$, Groves $\mathrm{AM}$ et al. Ventilation- perfusion scintigraphy to predict postoperative pulmonary function in lung cancer patients undergoing pneumonectomy. AJR 2006; 187: 1260-1265.

27. Corris PA, Ellis DA, Hawkins T, Gibson GJ. Use of radionuclide scanning in the preoperative estimation of pulmonary function after pneumonectomy. Thorax 1987; 42: 285-291.

28. Ohno $\mathrm{Y}$, Hatabu H, Higashino T et al. Dynamic perfusion MRI versus perfusion scintigraphy: prediction of postoperative lung function in patients with lung cancer. AJR 2004; 182: 73-78.

29. Iwasawa T, Saito K, Ogawa N, Ishiwa N, Kurihara H. Prediction of postoperative pulmonary function Rusing perfusion magnetic resonance imaging of the lung. J Magn Reson Imaging 2002; 15: 685-692. 